\title{
Uptake and impact of vaccinating primary school- age children against influenza: experiences of a live attenuated influenza vaccine programme, England, $2015 / 16$
}

Richard G Pebody ${ }^{1}$, Mary A Sinnathamby ${ }^{1}$, Fiona Warburton ${ }^{1}$, Nick Andrews ${ }^{1}$, Nicola L Boddington ${ }^{1}$, Hongxin Zhao ${ }^{1}$, Ivelina

Yonova ${ }^{2,3}$, Joanna Ellis ${ }^{1}$, Elise Tessier ${ }^{1}$, Matthew Donati ${ }^{4}$, Alex J Elliot ${ }^{5}$, Helen E Hughes ${ }^{5}$, Sameera Pathirannehelage ${ }^{2,3}$, Rachel

Byford $^{2,3}$, Gillian E Smith ${ }^{5}$, Simon de Lusignan ${ }^{2,3}$, Maria Zambon ${ }^{1}$

1. Public Health England (PHE), Colindale, London, United Kingdom

2. Royal College of General Practitioners (RCGP) Research and Surveillance Centre (RSC), London, United Kingdom

3. University of Surrey, Guildford, United Kingdom

4. Public Health England (PHE), Bristol, United Kingdom

5. Public Health England (PHE), Birmingham, United Kingdom

Correspondence: Richard Pebody (richard.pebody@phe.gov.uk)

Citation style for this article:

Pebody Richard G, Sinnathamby Mary A, Warburton Fiona, Andrews Nick, Boddington Nicola L, Zhao Hongxin, Yonova Ivelina, Ellis Joanna, Tessier Elise, Donati Matthew, Elliot Alex J, Hughes Helen E, Pathirannehelage Sameera, Byford Rachel, Smith Gillian E, de Lusignan Simon, Zambon Maria. Uptake and impact of vaccinating primary school-age children against influenza: experiences of a live attenuated influenza vaccine programme, England, 2015/16. Euro Surveill. 2018;23(25): pii=1700496. https://doi.org/10.2807/1560-7917.ES.2018.23.25.1700496

The 2015/16 influenza season was the third season of the introduction of an intra-nasally administered live attenuated influenza vaccine (LAIV) for children in England. All children aged 2-6 years were offered LAIV, and in addition, a series of geographically discrete areas piloted vaccinating school-age children 7-11 years old. Influenza $\mathrm{A}\left(\mathrm{H}_{1} \mathrm{~N}_{1}\right)$ pdmog was the dominant circulating strain during 2015/16 followed by influenza B. We measured influenza vaccine uptake and the overall and indirect effect of vaccinating children of primary school -age, by comparing cumulative disease incidence in targeted and non-targeted age groups in vaccine pilot and non-pilot areas in England. Uptake of $57.9 \%$ (range: $43.6-72.0$ ) was achieved in the five pilot areas for children aged 5-11 years. In pilot areas, cumulative emergency department respiratory attendances, influenza-confirmed hospitalisations and intensive care unit admissions were consistently lower, albeit mostly non-significantly, in targeted and non-targeted age groups compared with non-pilot areas. Effect sizes were less for adults and more severe endpoints. Vaccination of healthy primary school-age children with LAIV at moderately high levels continues to be associated with population-level reductions in influenza-related respiratory illness. Further work to evaluate the population-level impact of the programme is required.

\section{Background}

During the 2015/16 influenza season, England and the rest of the United Kingdom (UK) was in the third season of a new childhood influenza vaccination programme targeting healthy children with a recently licensed intra-nasally administered live attenuated influenza vaccine (LAIV). The programme ultimately aims to offer annual influenza vaccination to all children 2-16 years of age to both directly protect them, and, by reducing their rate of infection, indirectly protect others in the community - particularly those who may be at higher risk of severe disease following influenza [1]. In this third season, the LAIV programme was extended from offering the vaccine to all healthy children $2-4$ years of age to all children in school years 1 and 2, i.e. children 5 and 6 years of age across England. In addition, as in the 2 previous years, a series of five geographically discrete pilots were undertaken in England. In these pilots, the remaining healthy children of primary school age in school years 3 to 6 i.e. children aged 7-11 years, were also offered LAIV, with uptake exceeding $50 \%[2,3]$.

The key evidence supporting the introduction of the UK childhood LAIV programme was mathematical transmission modelling that predicted and quantified the future impact, combined with an economic evaluation to determine the most cost-effective approach [4]. Since then, recently published evidence from the UK has shown that LAIV has been effective in children over these first three seasons [5]. Furthermore, the first 2 years of the LAIV programme provided encouraging evidence, albeit often not statistically significant, showing that vaccinating children of primary school age was associated with reductions in incidence for a range of influenza disease indicators in both targeted 


\section{FIGURE 1}

Cumulative uptake of live attenuated influenza vaccine in primacy school-age children ${ }^{\mathrm{a}}$ in pilot areas, England, week 40 2015-week 202016

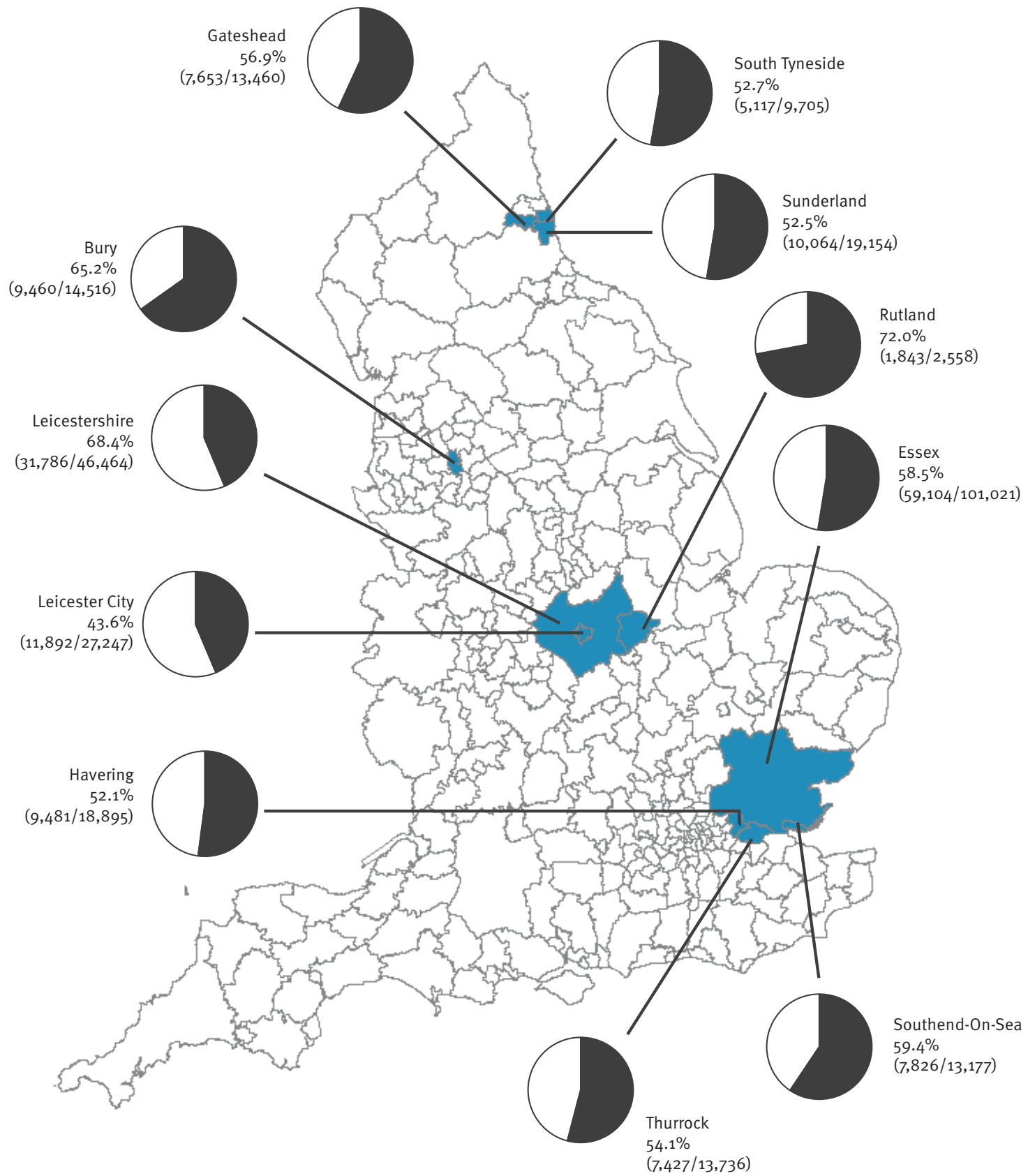

${ }^{a}$ Children 5 to 10 years of age, rising to 11 years of age.

The pilot areas are shown shaded on the map. The shaded area of each pie chart indicates the percentage of target children vaccinated.

Contains National Statistics data (C) Crown copyright and database right 2014.

and non-targeted age groups when comparing pilot and non-pilot areas in England [6,7]. To date, only limited data has been published internationally of the observed impact of such programmes [8-10].

The 2015/16 influenza season in the UK started late, with peak activity in week $11 / 12$, and was initially dominated by circulation of influenza $A\left(\mathrm{H}_{1} \mathrm{~N}_{1}\right)$ pdmog.
Disease impact was particularly seen in younger adults, resulting in large numbers of hospitalisations and intensive care unit (ICU) admissions in these age groups. However, neither level reached those observed in the last significant $\mathrm{A}\left(\mathrm{H}_{1} \mathrm{~N}_{1}\right)$ pdmog season of $2010 / 11$. The latter part of this recent season saw influenza $B$ circulation, particularly of the B/Victoria lineage [3]. End-of-season UK vaccine effectiveness (VE) analyses 


\section{FIGURE 2}

Cumulative primary care ILI surveillance indicators in primary school pilot and non-pilot areas (A) consultation rate and (B) positivity rate ${ }^{a}$ from the RCGP ILI surveillance network with integrated microbiological surveillance, England, week 40 2015-week 202016

A. RCGP ILI

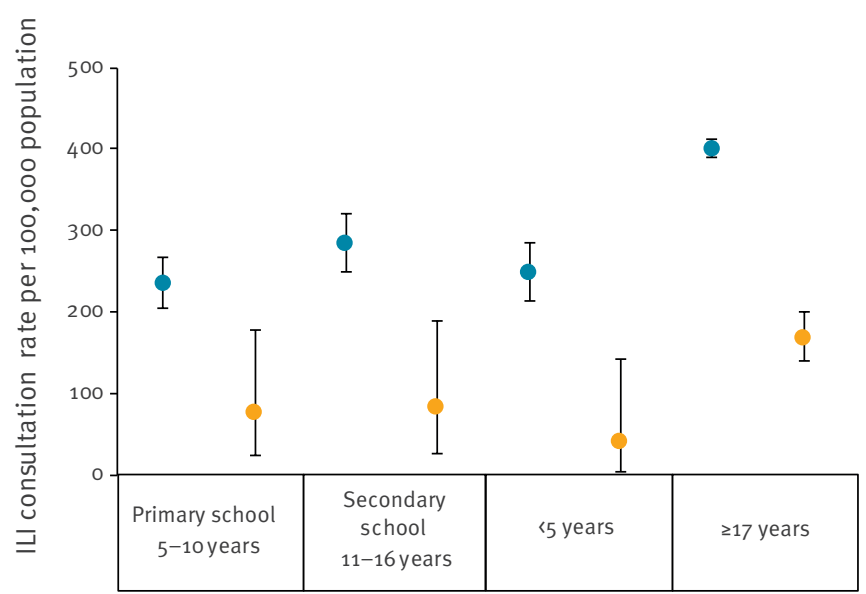

Age group
B. Sentinel positivity

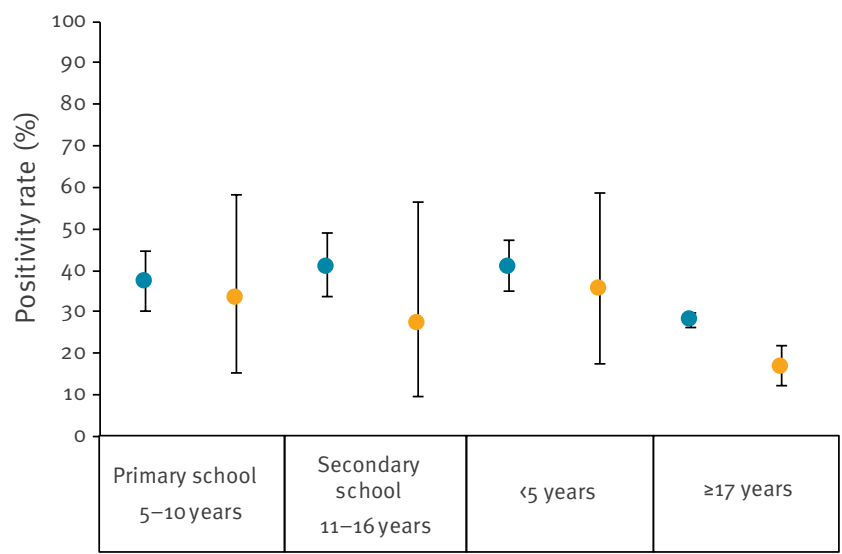

Age group

Pilot

Non-pilot

ILI: influenza-like illness; RCGP: Royal College of General Practitioners.

a RCGP only for consultation rate; RCGP and Specialist Microbiology Network for positivity rate.

Black bars indicate $95 \%$ confidence intervals.

for the $2015 / 16$ season reported that overall LAIV effectiveness in children 2 to 17 years of age in the UK was 57.6\% (95\% Cl: 25.1-76.0) [5]. However, data emerging from the United States (US) found little evidence of the effectiveness of LAIV in protecting children during the 2015/16 season, resulting in the Advisory Committee on Immunization Practices temporarily suspending the recommendation to use LAIV in the US [11]. The reason for the discrepancy in VE between the US and UK remains under investigation: a description of the potential population impact of vaccinating children with LAIV for the $2015 / 16$ season will help to guide the future paediatric vaccine strategy. The aim of this paper is to describe the uptake of influenza vaccine in children, to evaluate the indirect and total impact of vaccinating children of primary school age in England in the 2015/16 season against a range of influenzarelated indicators, and to compare these indicators in the pre-and post-paediatric influenza vaccine era.

\section{Methods}

The majority of the England pilot areas that started vaccinating primary school-age children with LAIV in $2013 / 14$ continued with the programme in 2015/16 $[6,7]$. All pilot areas delivered the programme through a school-based approach.

\section{Measuring vaccine uptake}

The target population for vaccination in pilot areas was defined as children of primary school age, i.e. children 5-10, but not 11 years or older (as defined by the child age on 1 September 2015) born between 1 September 2004 and 31 August 2010, resident in five areas in England: Greater Manchester (Bury); Leicestershire and Lincolnshire (Leicester City, Leicestershire, and Rutland); London (Havering); Essex (Essex, SouthendOn-Sea, Thurrock); and Northumberland \& Tyne and Wear (Gateshead, South Tyneside, Sunderland).

Commissioned data providers who were responsible for delivery of the childhood influenza programme in pilot areas collected and reported vaccination data to Public Health England (PHE) using ImmForm, a web-based reporting system [12]. Vaccine uptake was calculated from the number of children in the target population who received at least one dose of influenza vaccine in the period from 1 September 2015 until 31 January 2016. LAIV was offered to healthy children and at-risk children in whom vaccine was not contraindicated. For those at-risk children in whom LAIV was contraindicated, quadrivalent inactivated vaccine was offered instead. 


\section{FIGURE 3}

Cumulative secondary care surveillance indicators in primary school pilot and non-pilot areas from four surveillance networks, England, week 40 2015-week 202016

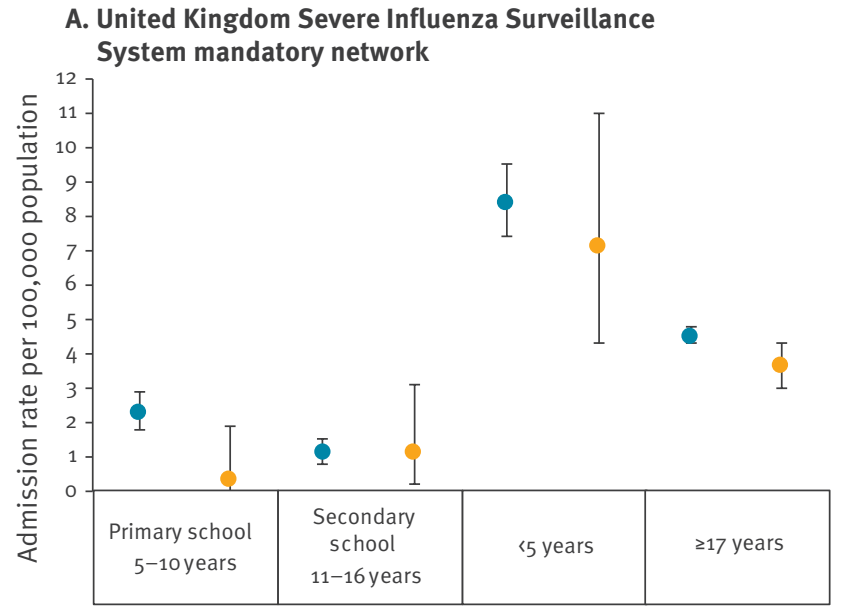

Age group

\section{Respiratory DataMart scheme}

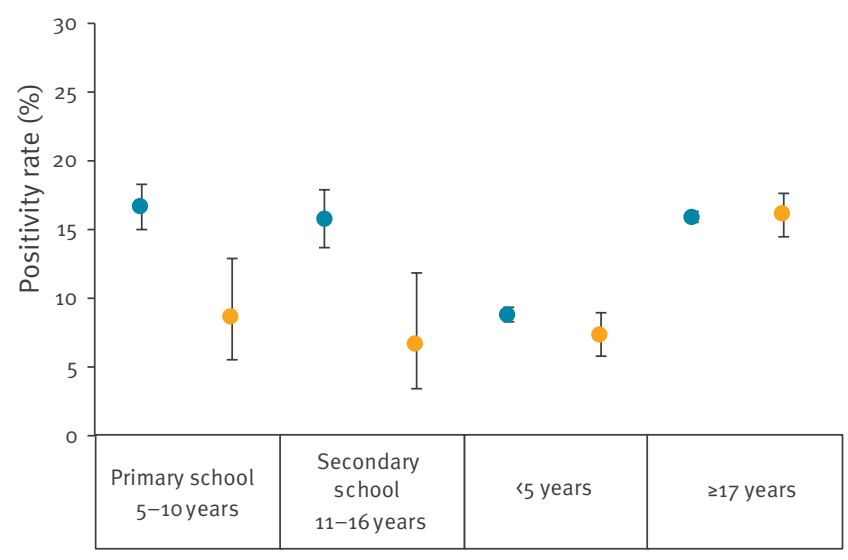

Age group

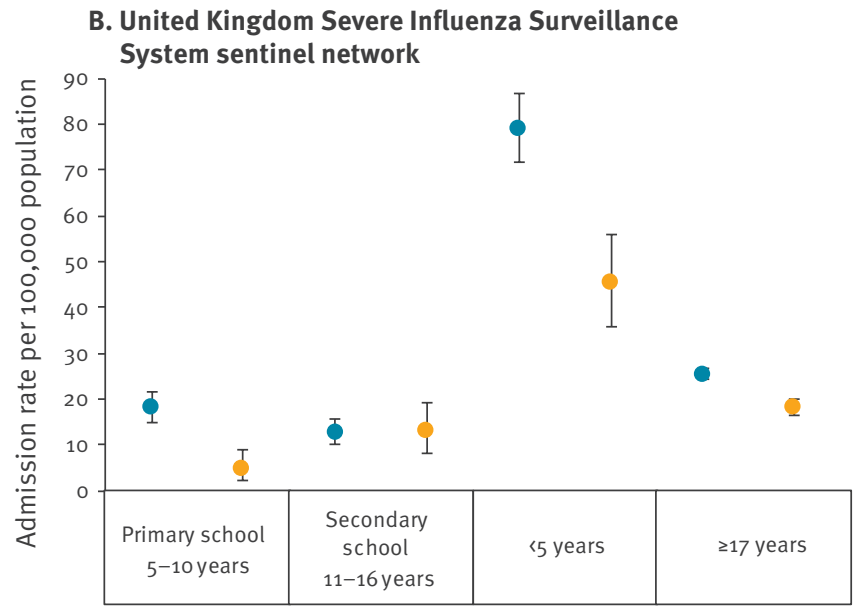

Age group

D. Emergency department attendance due to respiratory reasons

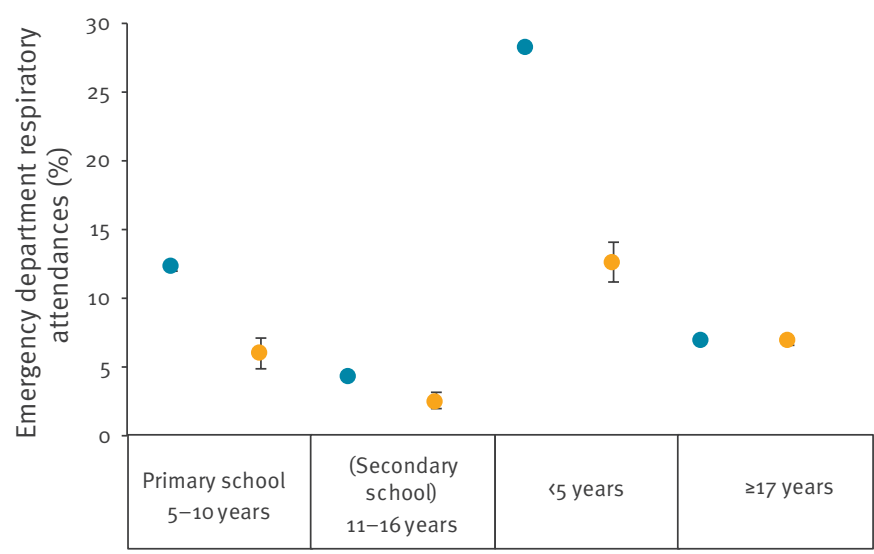

Age group

- Pilot Non-pilot

Black bars indicate $95 \%$ confidence intervals.

\section{Measuring school-age vaccine programme impact}

The period of the impact study ran from week 402015 until week 20 2016, which is when influenza transmission ceased for the $2015 / 16$ season [3].

The overall impact of the LAIV primary school-age programme for a range of virological and clinical endpoints in primary and secondary care as well as excess mortality was defined as Cumulative disease incidence in non-pilot areas - Cumulative disease incidence in primary school-age pilot areas.

As in previous studies, this was examined across four age groups to measure the impact of vaccination in targeted and non-targeted age groups. First, the impact in children of primary school age, i.e. 5-10 years of age (targeted age group). Second, the indirect impact in children less than 5 years of age, individuals 11-16 years of age and individuals 17 years of age (non-targeted age-groups) [7].

The cumulative, age-group-specific influenza indicators in pilot and non-pilot areas before vaccine programme introduction, i.e. 2011/12 and 2012/13, and after vaccine programme introduction, i.e. 2013/14, 2014/15 and 2015/16, in England were also compared.

\section{Data sources}

A range of sentinel surveillance systems were used to measure the impact of vaccinating children of primary school age. Additional sentinel general practitioners 


\section{FIGURE 4}

Cumulative weekly all-cause mortality in primary school pilot and non-pilot areas by influenza season, England, week 40 2011-20 2016

\section{A. 2011/12}

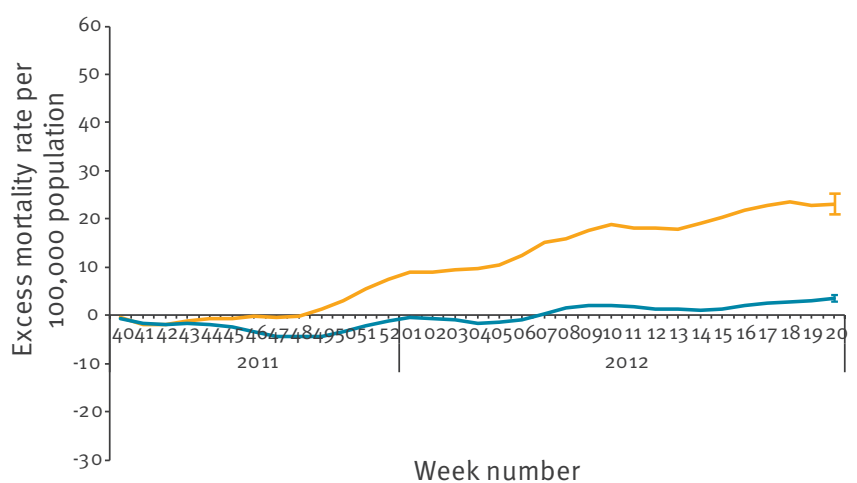

\section{C. $2013 / 14$}

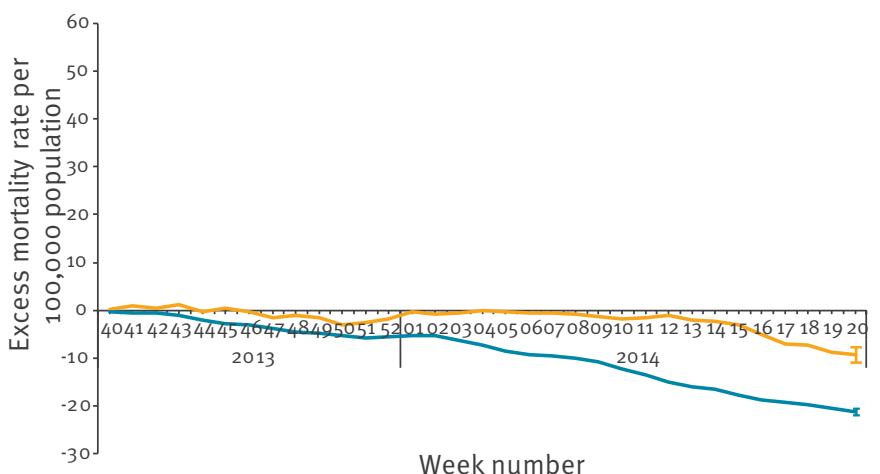

E. $2015 / 16$

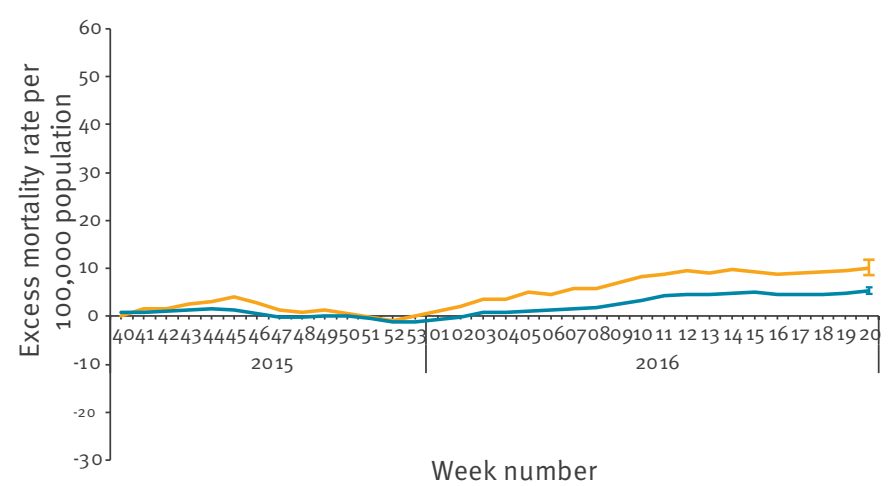

\section{B. $2012 / 13$}

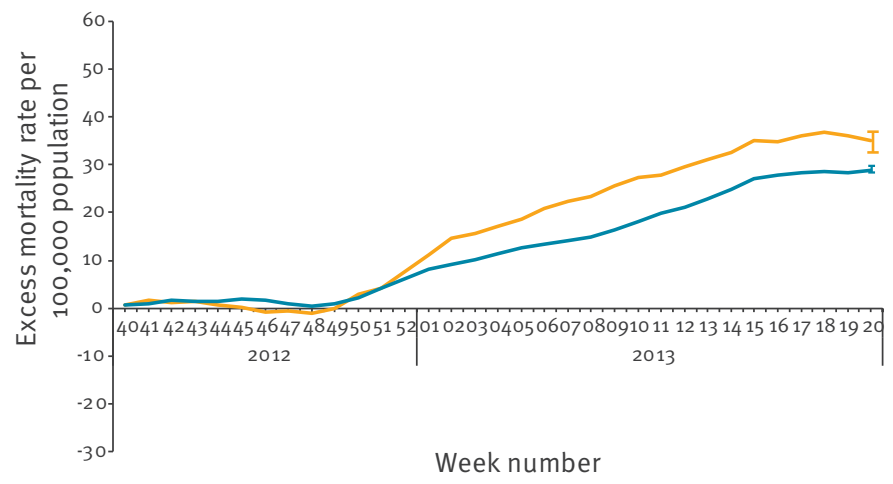

\section{2014/15}

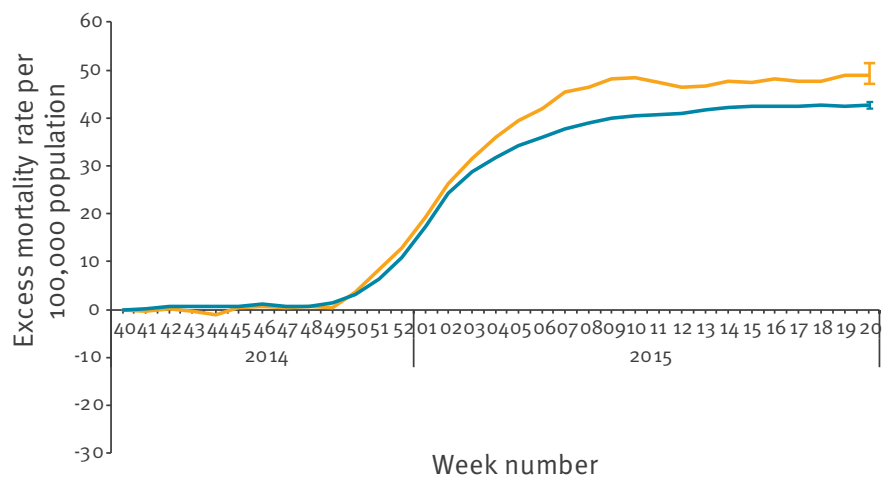

$$
\text { - Non-pilot }
$$

Panel A and and B display pre-paediatric vaccination programme introduction seasons and C,D and E post-vaccination programme seasons.

Pre-paediatric vaccination programme introduction were influenza seasons 2011/12 and 2012/13, and post paediatric vaccine programme introduction were seasons 2013/14; 2014/15; 2015/16. 


\section{FIGURE 5}

Cumulative weekly respiratory excess mortality in primary school pilot and non-pilot areas by influenza season, England, week 40 2011-week 202016

A. 2011/12

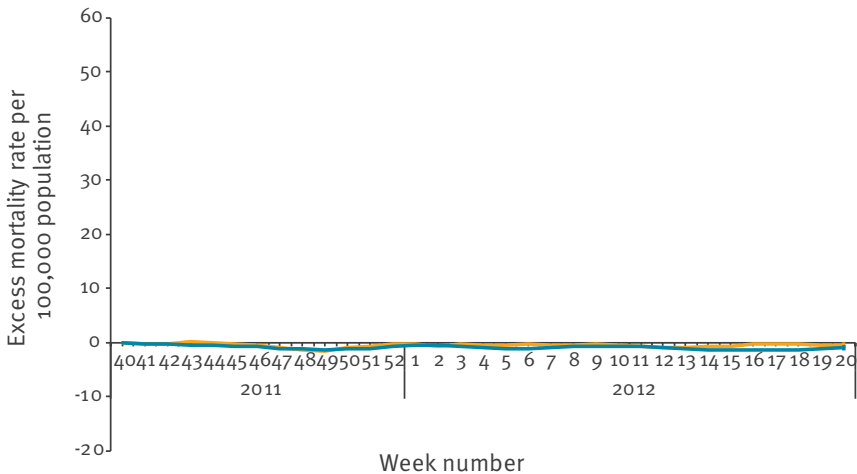

C. 2013/14

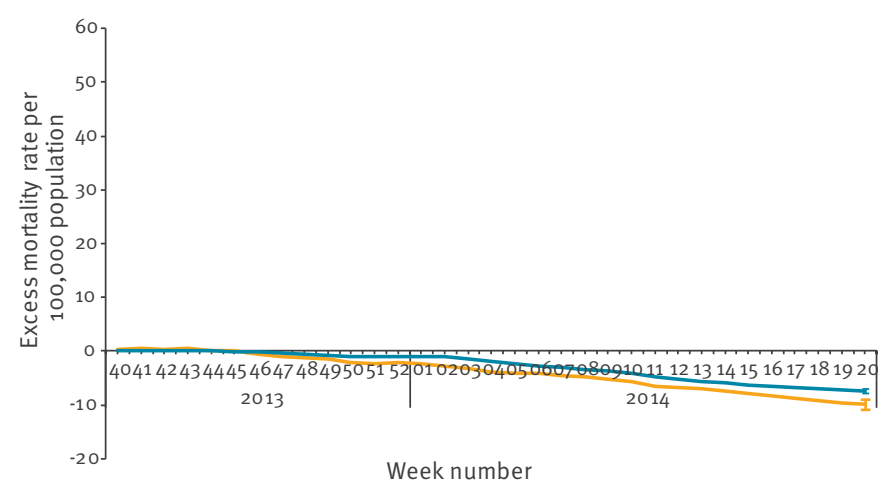

E. $2015 / 16$

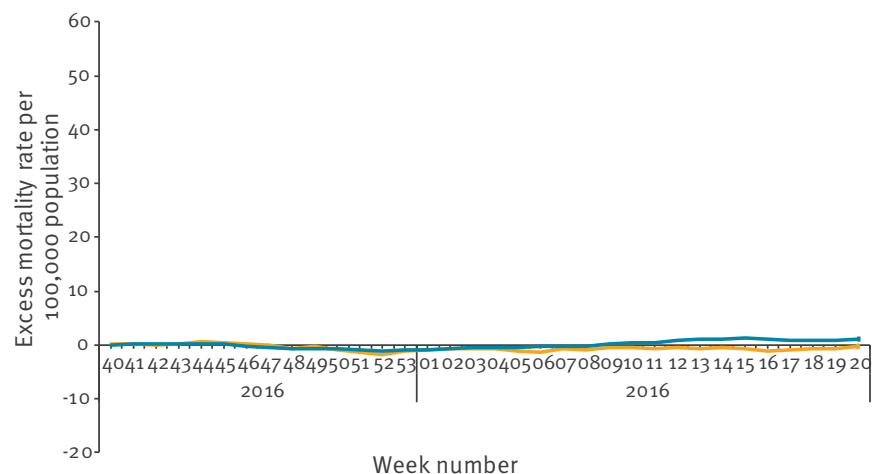

B.2012/13

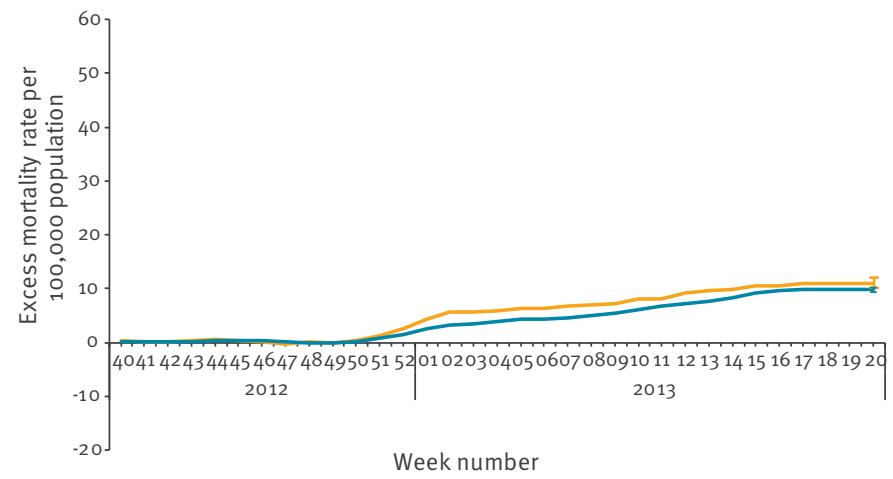

D. 2014/15

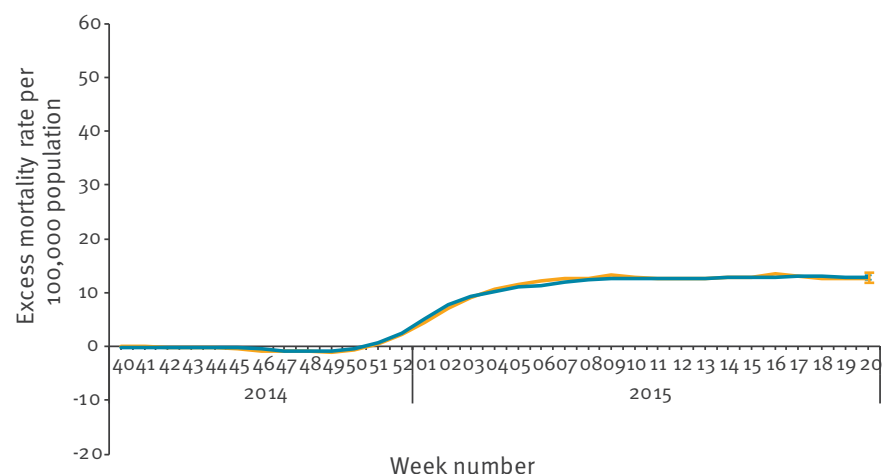

Week number

Panel A and B display pre-paediatric vaccination programme introduction seasons and C, D and E post-vaccination programme seasons.

Pre-paediatric vaccination programme introduction were influenza seasons 2011/12 and 2012/13, and post paediatric vaccine programme introduction were seasons 2013/14; 2014/15; 2015/16. 


\section{FIGURE 6}

Cumulative, age-specific influenza indicators in pilot and non-pilot areas, by notification systems, England, week 40 2011week $202016^{\mathrm{a}}$

« years

\section{A. RCGP}

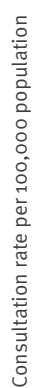

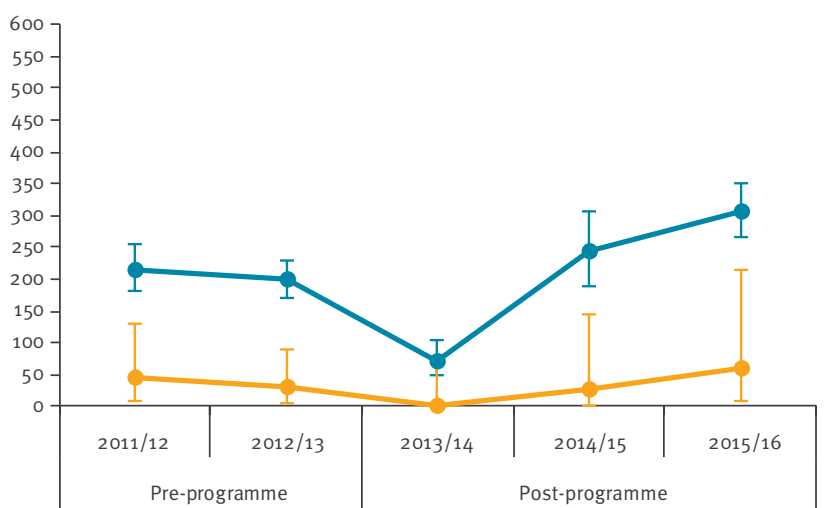

B. USISS sentinel
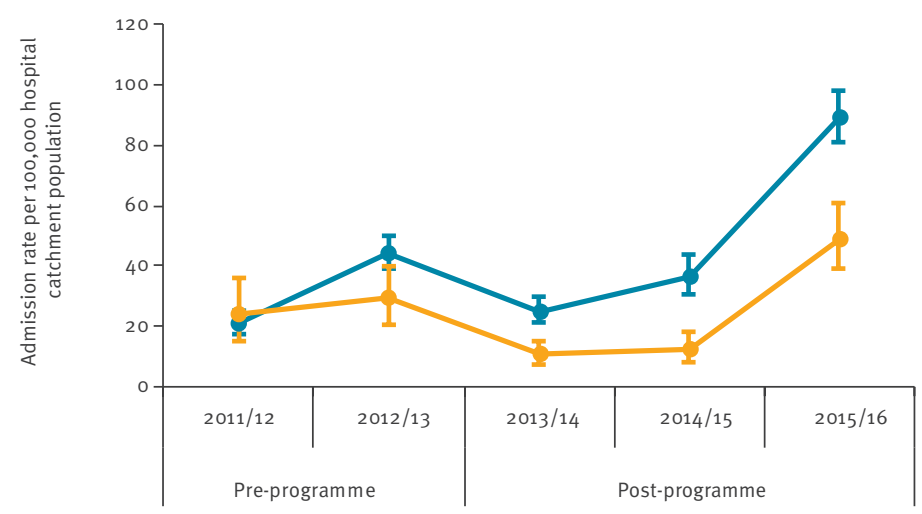

\section{USISS mandatory}
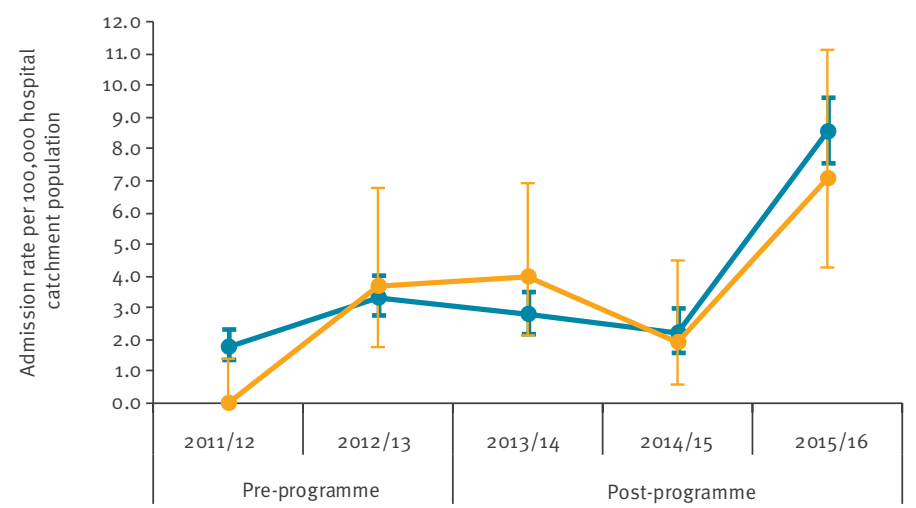
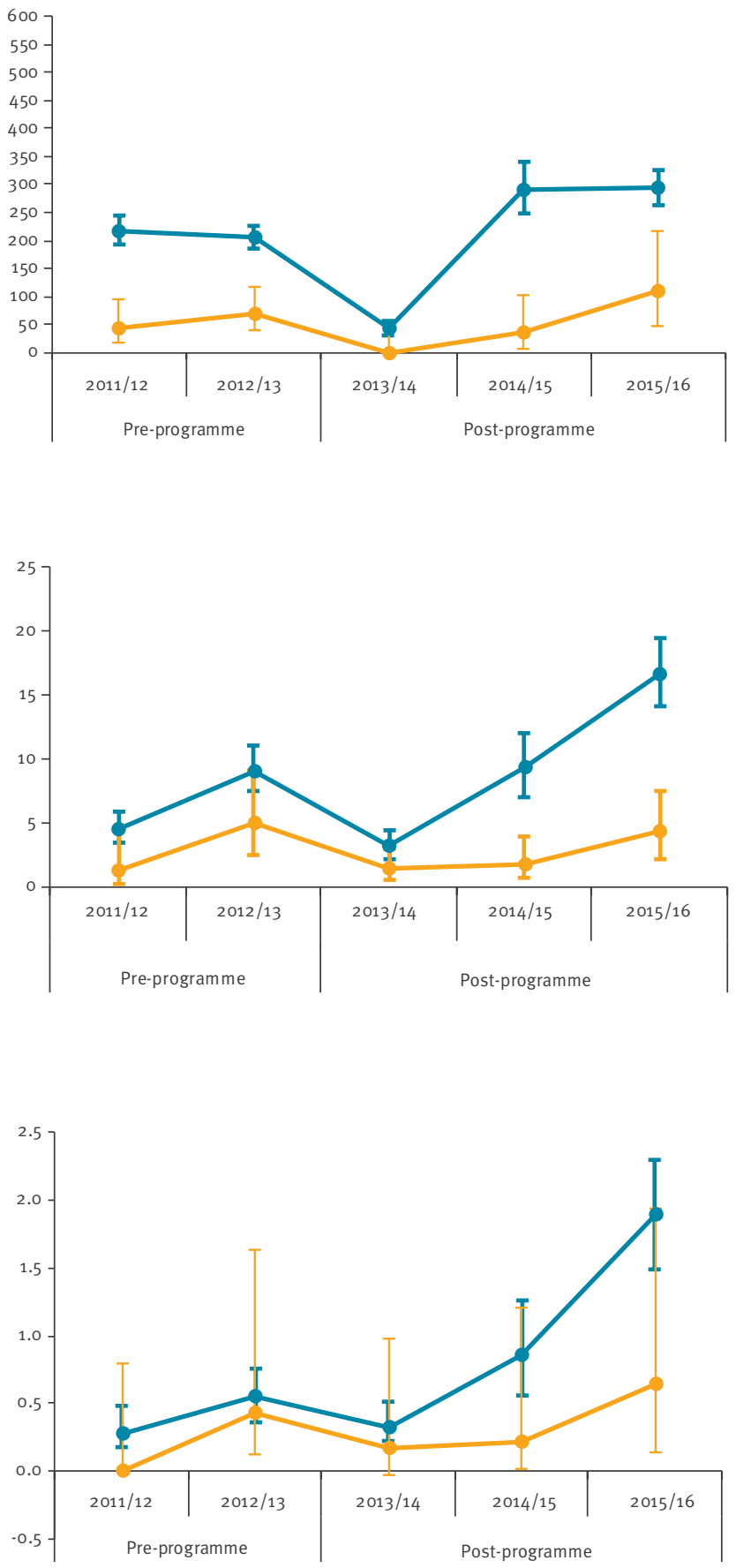

- Pilot - Non-pilot

ILI: influenza-like illness; RCGP: Royal College of General Practitioners; USISS: United Kingdom Severe Influenza Surveillance System. 


\section{FIGURE 7}

Cumulative, age-specific influenza indicators in pilot and non-pilot areas, by notification system, England, week 40 2011week $202016^{\mathrm{a}}$

15-44 years

\section{A. RCGP}

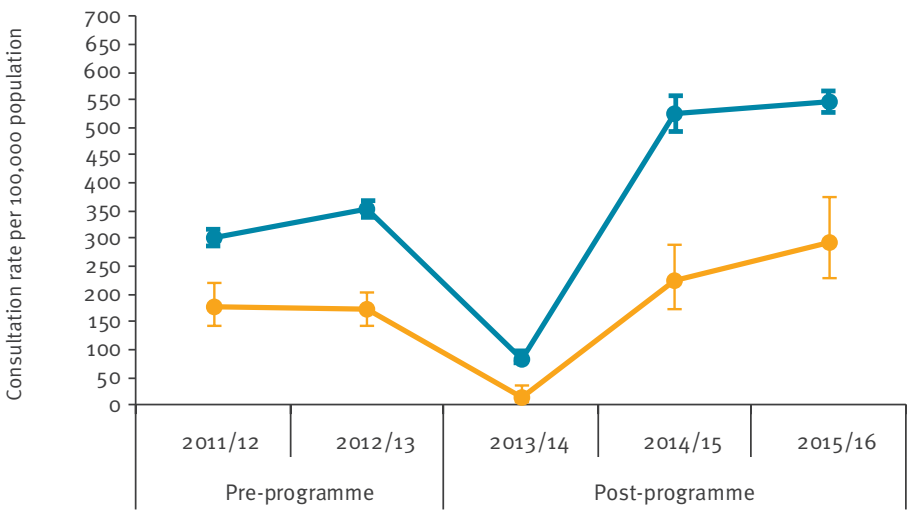

B. USISS sentinel

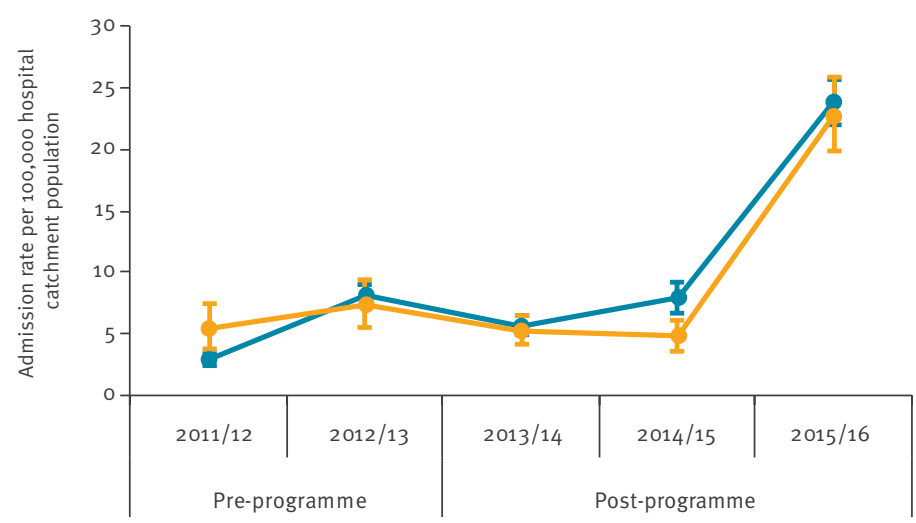

C. USISS mandatory

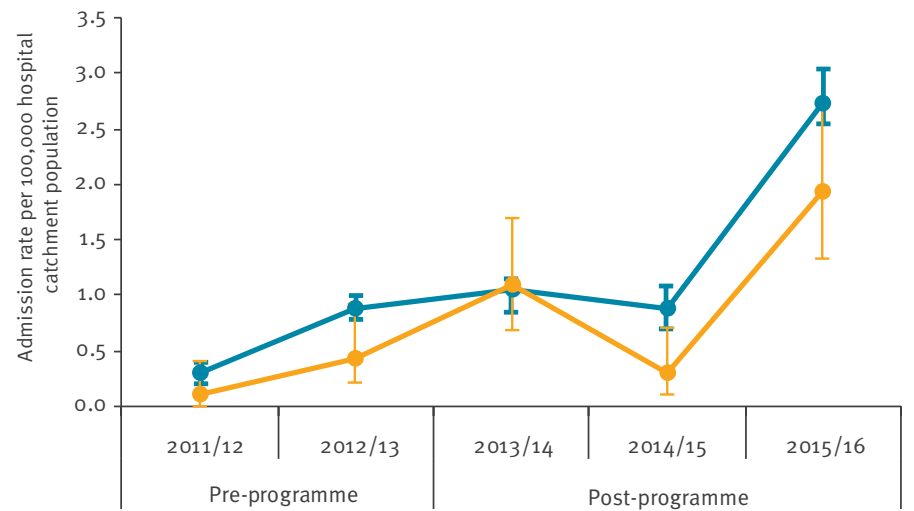

45-64 years

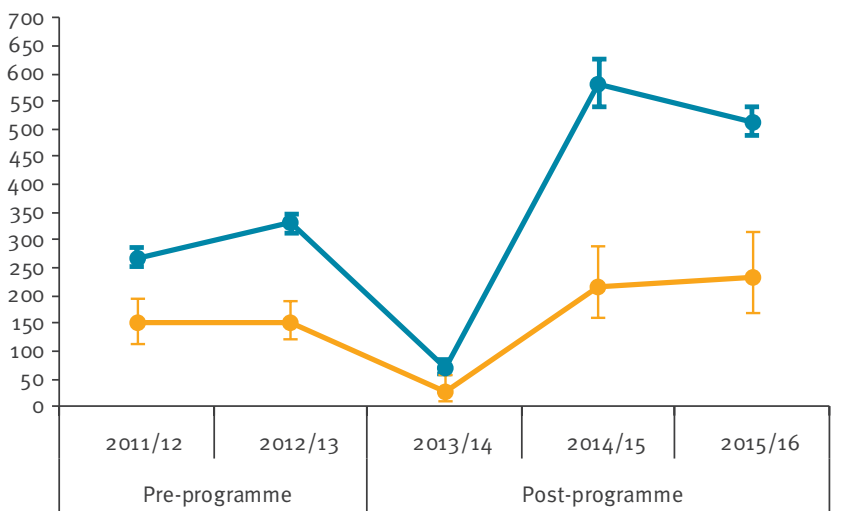

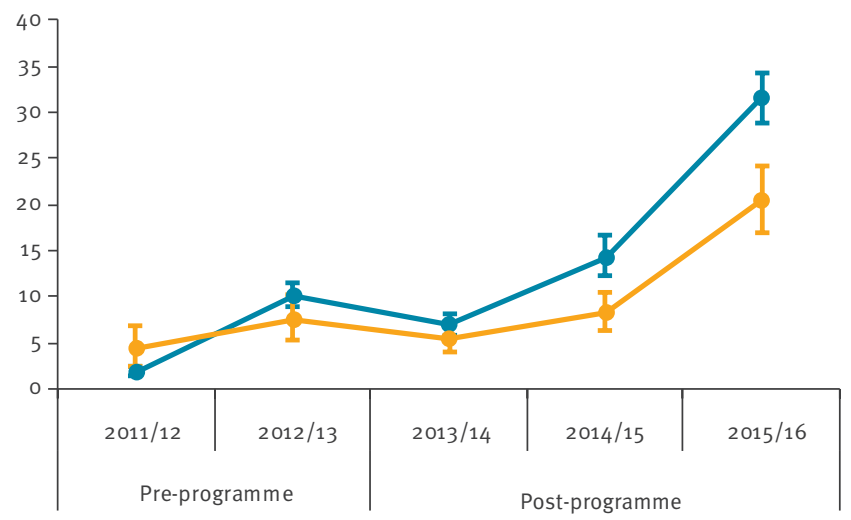

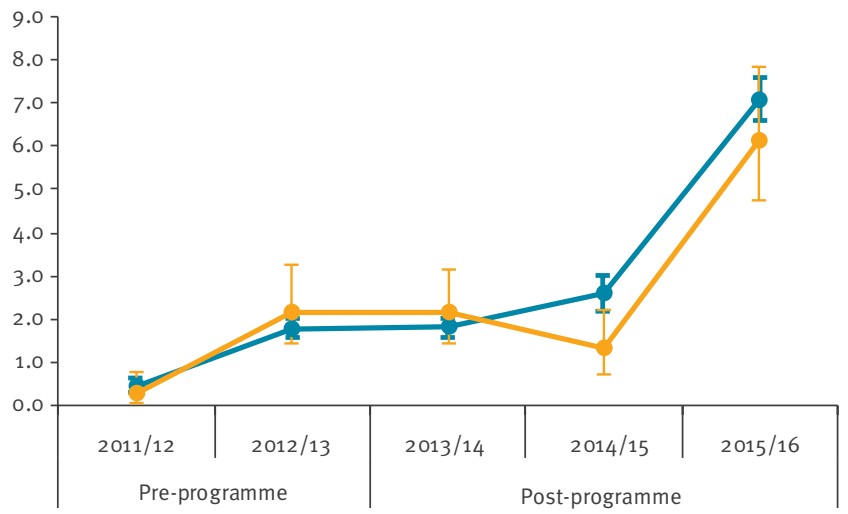

- Pilot - Non-pilot

ILI: influenza-like illness; RCGP: Royal College of General Practitioners; USISS: United Kingdom Severe Influenza Surveillance System.

a For the 2013/14 season, the data are based on week 402013 to week 152014 as per previously published work [6]. The primary pilot areas in the $2013 / 14$ season were applied to calculate rates at each reporting level. Similarly, for the 2014/15 season, the data are based on week 40 2014 to week 142015 as per previously published work [7]. The primary pilot areas in the 2014/15 season were applied to calculate rates at each reporting level, excluded secondary pilots areas. 


\section{FIGURE 8}

Cumulative, age-specific influenza indicators in pilot and non-pilot areas, England, week 40 2011-week $202016^{\mathrm{a}}$
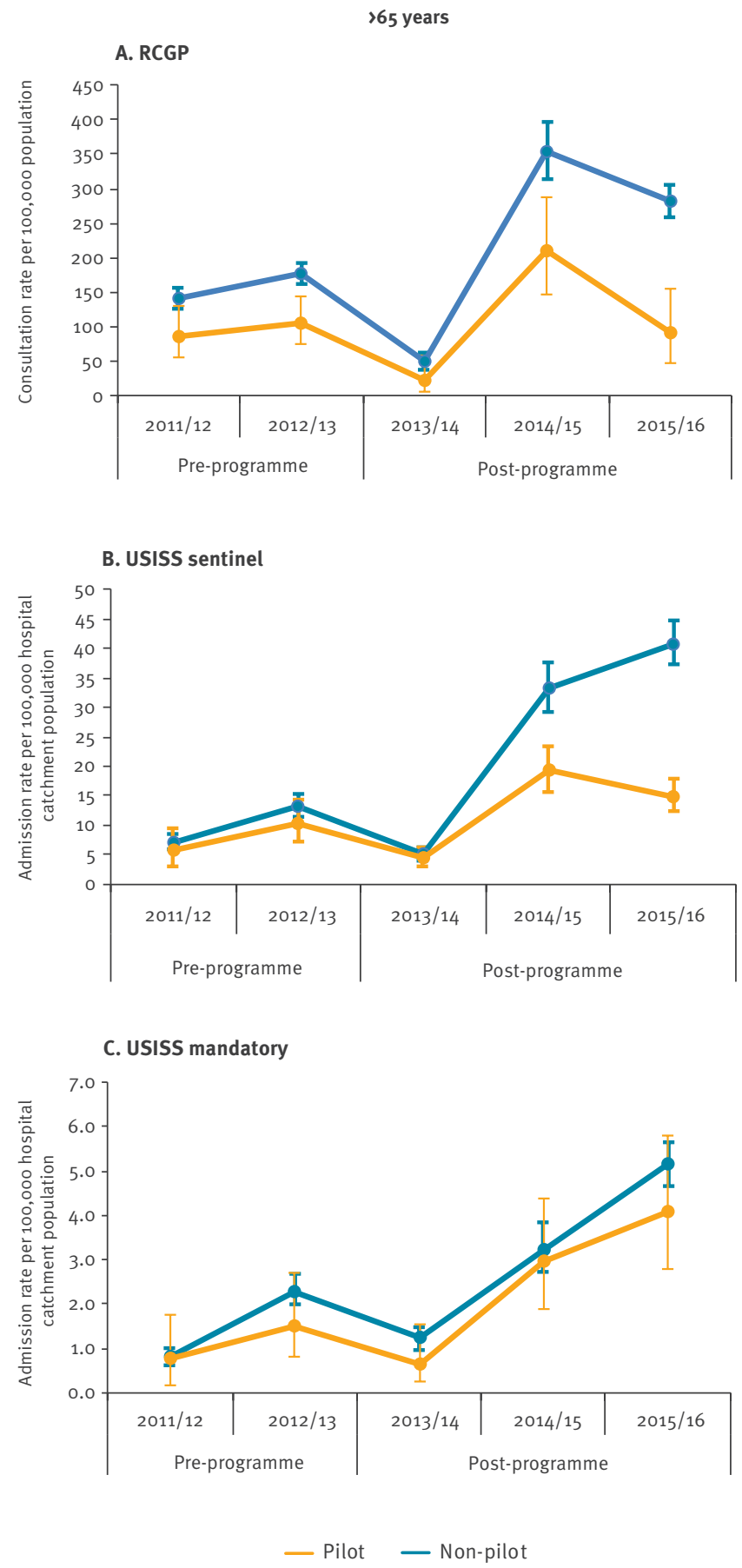

ILI: influenza-like illness; RCGP: Royal College of General Practitioners; USISS: United Kingdom Severe Influenza Surveillance System.

a For the 2013/14 season, the data are based on week 402013 to week 152014 as per previously published work [6]. The primary pilot areas in the $2013 / 14$ season were applied to calculate rates at each reporting level. Similarly, for the $2014 / 15$ season, the data are based on week 402014 to week 142015 as per previously published work [7]. The primary pilot areas in the $2014 / 15$ season were applied to calculate rates at each reporting level, excluded secondary pilots areas.
(GPs), emergency departments (ED) and hospitals were recruited in the pilot areas since the first season of the introduction of the LAIV programme in 2013/14.

\section{Primary care}

Primary care surveillance was undertaken through the Royal College of General Practitioners (RCGP) Research and Surveillance Centre (RSC) Weekly Returns Service sentinel GP network. This system reported weekly influenza-like illness (ILI) consultations in primary care. One hundred-forty-six RCGP practices participated in nonpilot areas and 10 practices in pilot areas. Seventy of these RCGP practices together with 22 practices from a further sentinel network, the Specialist Microbiology Network (SMN), collected respiratory swabs from a sample of patients consulting with ILI, regardless of vaccination status.

Secondary care

The UK Severe Influenza Surveillance System (USISS) includes two schemes. First, USISS sentinel, a voluntary network of 27 National Health Service (NHS) hospital trusts across England (22 in non-pilot areas and five in pilot areas in 2015/16), reported the weekly number of laboratory-confirmed influenza hospital admissions [13]. Estimated hospital catchment populations were used to calculate weekly laboratory confirmed hospitalisation rates per 100,000 population [14] as previously documented by pilot area and age group. Second, USISS mandatory, which involves all ICU and high dependency units (HDU) in England (136 units in non-pilot areas and 11 in pilot areas in 2015/16), reported the number of laboratory-confirmed influenza admissions each week. Admission rates by age group and pilot area were calculated as for the USISS sentinel scheme [13].

The Emergency Department Syndromic Surveillance System (EDSSS), is a sentinel network of emergency departments (ED) that monitors weekly ED attendances [15] and the proportion of all weekly attendances coded as respiratory in pilot (one ED) and non-pilot areas (24 EDs) by age group.

The Respiratory DataMart scheme (RDMS), collates and reports all influenza reverse-transcription-PCR (RT-PCR) respiratory swab results in a network of PHE and NHS laboratories in England; the majority of samples (>90\%) came from secondary care [16] and were used to compare the influenza cumulative positivity over the study period. Postcode of residence was used to classify whether a sample was taken from a patient residing in a pilot or non-pilot area. Swab positivity was compared by age group and pilot area.

\section{Excess mortality}

Routine death registration data from the Office for National Statistics was used to calculate excess mortality each week using the European Monitoring of Excess Mortality for Public Health Action (EuroMOMO) standard algorithm [17]. The observed number of 
TABLE 1

Adjusted impact of vaccinating primary school-age children on selected primary care influenza surveillance indicators, England, influenza season, 2015/16

\begin{tabular}{|c|c|c|c|c|c|c|}
\hline \multirow{2}{*}{\multicolumn{2}{|c|}{ Age group }} & \multirow[t]{2}{*}{ Measure } & \multicolumn{2}{|c|}{$\begin{array}{l}\text { RCGP ILI consultation rate (per 100,000 } \\
\text { population) }\end{array}$} & \multicolumn{2}{|c|}{ Sentinel influenza swab positivity (\%) } \\
\hline & & & Non-pilot area & Pilot area ${ }^{b}$ & Non-pilot area & Pilot area ${ }^{b}$ \\
\hline \multirow{5}{*}{ Primary school } & \multirow{5}{*}{ 5-10 years } & Rate & 234.7 & 75.8 & 37.3 & 33.3 \\
\hline & & $(\mathrm{n} / \mathrm{N})$ & $(225 / 95,857)$ & $(5 / 6,593)$ & $(63 / 169)$ & $(5 / 15)$ \\
\hline & & Risk difference & \multirow{3}{*}{ Ref } & -158.9 & \multirow{3}{*}{ Ref } & -4.0 \\
\hline & & OR $(95 \% \mathrm{Cl})$ & & $0.31(0.08$ to 1.15$)$ & & $0.96(0.23$ to 4.03$)$ \\
\hline & & $p$ value & & 0.080 & & 0.961 \\
\hline \multirow{5}{*}{ Secondary school } & \multirow{5}{*}{$\begin{array}{l}11-16 \\
\text { years }\end{array}$} & Rate & 283.0 & 81.1 & 40.9 & 27.3 \\
\hline & & $(\mathrm{n} / \mathrm{N})$ & $(249 / 87,979)$ & $(5 / 6,164)$ & $(63 / 154)$ & $(3 / 11)$ \\
\hline & & Risk difference & \multirow{3}{*}{ Ref } & -201.9 & \multirow{3}{*}{ Ref } & -13.6 \\
\hline & & OR $(95 \% \mathrm{Cl})$ & & 0.28 (0.08 to 0.91$)$ & & $0.54(0.14$ to 2.12$)$ \\
\hline & & $\mathrm{p}$ value & & 0.034 & & 0.379 \\
\hline \multirow{10}{*}{ Other age groups } & \multirow{5}{*}{$<5$ years } & Rate & 248 & 39.5 & 41.1 & $35 \cdot 3$ \\
\hline & & $(\mathrm{n} / \mathrm{N})$ & $(197 / 79,449)$ & $(2 / 5,057)$ & $(99 / 241)$ & $(6 / 17)$ \\
\hline & & Risk difference & \multirow{3}{*}{ Ref } & -208.5 & \multirow{3}{*}{ Ref } & -5.8 \\
\hline & & OR $(95 \% \mathrm{Cl})$ & & $0.14(0.02$ to 1.18$)$ & & $0.97(0.16$ to 5.71$)$ \\
\hline & & $\mathrm{p}$ value & & 0.071 & & 0.971 \\
\hline & \multirow{5}{*}{$\geq 17$ years } & Rate & 400.3 & 167.5 & 28.1 & 16.5 \\
\hline & & $(\mathrm{n} / \mathrm{N})$ & $(4,529 / 1,131,418)$ & $(122 / 72,842)$ & $(648 / 2,308)$ & $(39 / 237)$ \\
\hline & & Risk difference & \multirow{3}{*}{ Ref } & -232.8 & \multirow{3}{*}{ Ref } & -11.6 \\
\hline & & OR $(95 \% \mathrm{Cl})$ & & $0.37(0.16$ to 0.90$)$ & & $0.52(0.32$ to 0.84$)$ \\
\hline & & $\mathrm{p}$ value & & 0.029 & & 0.008 \\
\hline
\end{tabular}

$\mathrm{Cl}$ : confidence interval; ILI: influenza-like illness; OR: odds ratio; RCGP: Royal College of General Practitioners.

${ }^{\text {a }}$ Week 402015 to week 202016.

b Includes primary school pilot areas.

$p$ values $<0.05$ are in bold.

weekly death occurrences, corrected for reporting delay, was compared with the expected number of deaths, based upon historical patterns, to determine if there was statistically significant excess mortality. Excess mortality was estimated in both non-pilot and pilot areas based upon place of usual residence. The algorithm was applied to both all-cause mortality and death registrations where respiratory, ICD-10 'J' code, was the primary cause of death [18].

\section{Statistical methods}

Cumulative disease incidence rates per 100,000 population were calculated for the RCGP, USISS sentinel and USISS mandatory schemes, by summing the number of weekly disease episodes (from week 402015 to week 20 2016) over the average weekly population at risk based on the GP registered or hospital catchment population respectively. Calculations were undertaken overall and by age group for both pilot and non-pilot areas. Exact Poisson confidence intervals $(\mathrm{Cl})$ were calculated.

Cumulative influenza swab positivity for the GP swabbing (from RCGP and SMN) and RDMS were calculated by summing the number of positive samples over the total number of samples tested in the study period. Cumulative proportion of ED attendances coded as respiratory were calculated by summing the total number of respiratory coded ED attendances over the total number of ED attendances with a diagnosis during the study period. Calculations were undertaken overall and by age group and pilot area. Exact Cls were calculated. To measure the impact of primary school vaccination, the non-pilot areas were set as reference and odds ratios (ORs) and 95\% Cls were calculated by age group and surveillance system. To adjust for clustering at the reporting unit level, e.g. by GP, hospital, laboratory, data were converted to binomial individual level across schemes and random effects logistic regression was undertaken.

Cumulative excess mortality rates by pilot and nonpilot area were calculated by summing the difference between observed and expected weekly deaths over the study period, and using the resident population in pilot and non-pilot areas. 


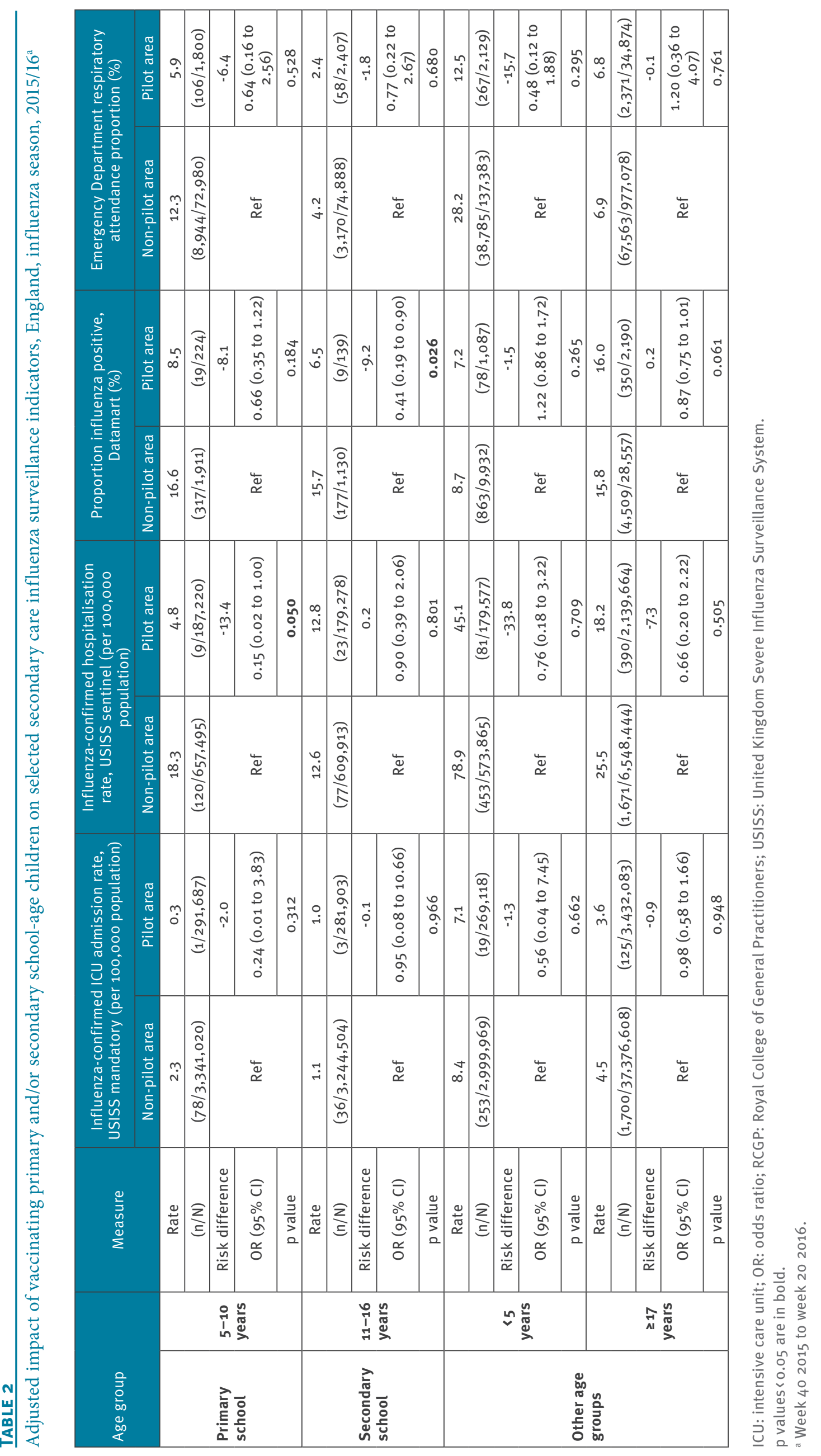


Comparison for the post-introduction (2013/14, $2014 / 15,2015 / 16)$ and pre-introduction periods $(2011 / 12,2012 / 13)$ was undertaken for the cumulative, age-specific influenza incidence in pilot and non-pilot areas. The pre-vaccination pilot areas were the same as those defined for the $2015 / 16$ season.

\section{Laboratory methods}

Influenza laboratory confirmation of samples from primary and secondary care was undertaken on respiratory samples using comparable real-time PCR methods able to detect circulating influenza $A$ and influenza $B$ viruses $[19,20]$. Samples from the RCGP sentinel GP scheme were sent to the PHE Reference Virus Unit in Colindale; samples from the SMN sentinel GP scheme and secondary care were sent to one of the network of specialist PHE microbiology laboratories (SMN scheme) or NHS laboratories elsewhere in England (secondary care).

\section{Results}

\section{Vaccine uptake}

The total target population for the primary school pilots was estimated to be 279,933 primary school-age children.

An estimated 162,013 primary school-age children in pilot areas received at least one dose of influenza vaccine resulting in an overall uptake of $57.9 \%$. This ranged from $43.6 \%$ to $72.0 \%$ at the pilot-site level (Figure 1 ). Uptake by school year group ranged from $62.6 \%$ in year 1 (children 5 to 6 years of age), $60.1 \%$ in year 2 (children 6 to 7 years of age), $57.2 \%$ in year 3 (children 7 to 8 years of age), $56.2 \%$ in year 4 (children 8 to 9 years of age), $56.0 \%$ in year 5 (children 9 to 10 years of age), to $54.7 \%$ in year 6 (children 10 to 11 years of age).

Influenza vaccine uptake achieved in children 2-4 years of age in primary school pilot areas was $34.0 \%$ in 584 GP practices compared with $34.4 \%$ in 7,029 GP practices in non-pilot areas elsewhere in England. For children in school years 1 and 2, i.e. children 5 and 6 years of age, uptake was $61.4 \%(58,920 / 96,036)$ in pilot areas compared with $53 \%(658,008 / 1,240,567)$ in non-pilot areas elsewhere in England.

\section{School age vaccine programme impact}

\section{Patterns of activity}

The cumulative ILI consultation rate and sentinel GP swab positivity in primary care, ED respiratory attendances, RDMS influenza positivity and ICU/HDU rates in secondary care from week 402015 to week 202016 were consistently lower in primary school-age pilot areas compared with non-pilot areas in both the targeted and non-targeted age groups (Figures 2 and 3). These differences were less marked for the sentinel GP swab positivity, RDMS indicators and laboratoryconfirmed ICU admissions particularly in the older, non-targeted age group of individuals 17 years of age and over.

All-cause and respiratory excess mortality

All-cause excess mortality was significantly higher in pilot areas during both the pre-vaccine (2011/12 and 2012/13) and post-vaccine period (2013/14, 2014/15 and 2015/16) (Figure 4). For all-age respiratory deaths, there was no significant difference between pilot and non-pilot areas during the pre-vaccine period (2011/12 and 2012/13). However, in the post-vaccine period, cumulative excess respiratory deaths were significantly lower in both 2013/14 and 2015/16 seasons (Figure 5).

Pre-vaccination information for indicators with available data

Data were available for RCGP ILI and influenza confirmed hospitalisations and ICU admissions. During the two seasons before the start of the childhood vaccination programmes, the cumulative ICU/HDU admission and hospitalisation rates for influenza were similar between the targeted and non-targeted age groups in pilot areas compared to those in non-pilot areas. In comparison, GP ILI consultation rates were consistently lower during the two seasons prior to the programme introduction in the pilot areas compared with nonpilot areas. For all indicators, there was a divergence between pilot and non-pilot areas in both targeted and non-targeted age groups with the introduction of the childhood influenza vaccine programme in 2013/14 with a relative reduction for indicators in pilot areas compared to non-pilot areas (Figure 6, 7, 8).

Adjusted impact for primary and secondary care surveillance indicators

Vaccinating primary school age children resulted in significant reductions in cumulative incidence/laboratory-confirmed positivity in primary care indicators for ILI and swab positivity in adults when comparing pilot with non-pilot areas and adjusting for clustering (Table 1). There were also non-significant reductions for ILI GP consultations and swab positivity in both children of primary school age and thoseless than 5 years of age (Table 1)

For the secondary care indicators, i.e. for influenzaconfirmed hospitalisations and ICU admissions, ED attendances and DataMart positivity, reductions were seen in all instances in the targeted age group when comparing pilot to non-pilot areas, though this was only statistically significant for laboratory-confirmed hospitalisations (Table 2 ). The size of these reductions was less and non-significant when examining childrenless than 5 years of age and those of secondary school age. There was little evidence of any reduction for these indicators when comparing pilot and nonpilot areas among adults (Table 2). 


\section{Discussion}

This study assesses the uptake of LAIV and evaluates the impact of the recently implemented LAIV programme for children in England that was targeted at primary school-age children in discrete geographical pilot areas during the 2015/16 influenza season. We found similar levels of uptake during this season, when compared with the first two seasons and that vaccinating children of primary school age was associated with reductions in incidence for a range of surveillance indicators in England. This effect was most evident in areas where all children of primary school age had been targeted, with the impact most noticeable in targeted age groups. The size of the effect was less for more severe endpoints such as excess respiratory mortality, and for non-targeted age groups e.g. adults and secondary school-age children.

The 2015/16 influenza season was characterised by significant numbers of hospitalisations and ICU admissions and some fatalities among younger adults, an observation consistent with the circulation of influenza $\mathrm{A}\left(\mathrm{H}_{1} \mathrm{~N}_{1}\right)$ pdmog virus [3]. We observed decreases in influenza in primary school-age children (and indirectly in children under the age of 5 years, where the burden of influenza is recognised to be highest) together with smaller indirect reductions in secondary school-age children and adults in primary school age pilot areas. These indirect reductions seen for primary care consultations, laboratory-confirmed hospitalisations, ICU/ HDU admissions and ED attendances, however, were not statistically significant. As seen in the first two seasons of the programme, the effect sizes generally became smaller as the endpoints were more severe $[6,7]$, which is consistent with publications from elsewhere [8-10]; in particular, a study by King et al., who reported significant reductions in medically attended acute respiratory illnesses (MAARI) emergency department visits in children and young adults, but less so for hospitalisations (particularly in the elderly) associated with increases in LAIV uptake in primary school-age children [10].

We report good uptake levels in primary school-age children in pilot areas. A study by Calder et al. found that school-based influenza vaccine programmes achieved better equity by ethnicity and deprivation, though primary care delivery can also achieve important increases in uptake [21]. This reinforces this approach as a model of delivery for vaccinating children of school age.

A recent systematic review identified some evidence that vaccinating children can provide indirect benefits particularly against milder endpoints, but highlighted that larger scale studies were required against a range of endpoints in different settings [22]. Our study starts to address that need. The findings in this article are also encouraging in the light of observations in the US in 2015/16, where observational studies indicated that LAIV has had little or no effect among children [11]. This is in contrast to findings of moderate VE in other geographical settings such as the UK, Canada and Finland [23]. The reasons for these observations remain under investigation, though preliminary work has suggested impaired replicability of the A/California-like LAIV strain A/Bolivia ( $\left.\mathrm{H}_{1} \mathrm{~N}_{1}\right)$ pdmog in 2015/16 [24]. This strain has since been updated in the vaccine, so it will be important to evaluate the direct and indirect population impact of this new LAIV vaccine virus.

The reductions we observed occurred in a season in which new genetic subgroups in influenza $A\left(\mathrm{H}_{1} \mathrm{~N}_{1}\right)$ pdmog viruses emerged (6B.1 and 6B.2) and circulated as the predominant strains. These factors raised some concerns about possible vaccine mismatch, together with the end of season LAIV VE findings of $58 \%$ (overall) and of $42 \%$ against $A\left(\mathrm{H}_{1} \mathrm{~N}_{1}\right)$ pdmog in children 2-17 years of age [5]. Our results suggest that average uptake levels of $58 \%$ among all primary school-age children compared with the rest of the country - where only primary school-age children in school years 1 and 2 were offered vaccine, will result in reduction in influenza transmission in the local population. This is evidenced by observation of both direct and indirect impacts for a range of indicators in primary and (to a lesser extent) secondary care in these local areas.

Although there were reductions in a range of clinical endpoints in pilot compared with non-pilot areas in young adults, the differences were non-significant and became less for more severe indicators and the older age groups. The lesser effects observed could be related to how children interact with vulnerable groups such as the elderly particularly in settings such as care homes; other studies have also not been able to determine a significant difference [10]. Further research is planned to look at these differences, as this is where much of the health economic benefits of a school-age influenza vaccination programme were projected to be derived [4].

This study builds upon methodology developed in the first two seasons of the recently established childhood LAIV programme in order to evaluate its uptake and impact. The use of population-level data sources is a strength of this study, as we were able to compare our findings, in relation to vaccine uptake, with earlier published research $[6,7]$ and assess their impact across a range of indicators when primary school children were targeted. Examination of historical data suggests some caution is needed in interpretation, however, as there are pre-vaccine era programme differences in regard to primary care ILI consultation rates between pilot and non-pilot areas. The practices in pilot areas are more likely to have been newly recruited, which may explain pre-vaccination differences in reporting practice. The apparent effect sizes of this particular indicator should thus not be overestimated, with the majority of them non-significant in the models, which also take into account clustering at the reporting unit level. The ongoing roll-out of the national programme to increasing 
age cohorts of school children (in 2016/17, the programme additionally included children aged 3 and 7 years and in 2017/18 to children aged 8 years) will result in less notable differences in vaccine uptake between pilot and non-pilot areas; and thus the opportunity to undertake such comparative observational studies between geographical areas is, therefore, diminishing. Finally, the size of the pilot areas is relatively small, so results should be interpreted with caution as we had limited power to detect significant differences, particularly for more severe endpoints.

The differential roll-out of the LAIV programme across the countries of the UK, with Scotland and Northern Ireland vaccinating primary school-age children and Wales secondary school-age children in $2015 / 16$ has shown some early encouraging signs in relation to reductions in primary care consultations for those countries vaccinating primary school-age children [3]. This study in England provides further important opportunities to understand the population level impacts of the universal paediatric influenza vaccination programme.

\section{Conclusion}

In conclusion, our findings support the on-going roll out of the national LAIV programme for children of primary school age. Further work will need to be undertaken to evaluate the impact of the LAIV programme against a range of endpoints, in particular, the more severe ones such as those against mortality and to investigate the discordance observed between the UK and US paediatric programmes.

\section{Acknowledgements}

The authors would like to acknowledge all the patients involved; the PHE and NHS staff in each of the vaccine pilot sites who were responsible for planning and delivering the LAIV -school age programme; Mariya Hriskova, Filipa Ferreira, Ana Costa and David Mullet of the University of Surrey; all the participating general practices of the RCGP Research and Surveillance Centre Unit sentinel scheme; all participating emergency departments in the Emergency Department Syndromic Surveillance System and the Royal College of Emergency Medicine; Nisha Oppilamany, Sophia Steinberger and Bersabeh Sile of PHE and all the participants of the UK Severe Influenza Surveillance Scheme; and Praveen SebastianPillai and the staff of the PHE Respiratory Virus Unit, Paul Loveridge of the PHE Real-time Syndromic Surveillance Team and contributing PHE and NHS laboratories. This work was supported by Public Health England as part of an ongoing evaluation of the introduction of the new childhood influenza vaccination programme. This project has received funding from the European Union's Horizon 2020 research and innovation programme under grant agreement No 634446.

\section{Conflict of interest}

None declared.
Authors' contributions

RP led the design of the study and study group; all (MS, FW, $N A, N B, H Z, I Y, J E, E T, M D, A E, H H, S P, R B, G S, S L$ and $M Z$ ) were members of the study group and involved in data collection, management and analyses; MS, FW, NA and RP led the data analysis; MS undertook the summary analyses; $\mathrm{HZ}$ was responsible for the RDMS system, data management and analysis; NB was responsible for the USISS system, data management and analysis; $\mathrm{HH}, \mathrm{AE}$ and GS were responsible for the EDSSS data system management and analysis; IY worked directly with the practices and RB, SP and SdeL were responsible for the RCGP data system management and analysis; JE, MD and MZ were responsible for virological testing schemes; ET was responsible for monitoring of vaccine uptake in the pilot sites; RP drafted the initial manuscript; all co-authors reviewed and commented including approval of the final version.

\section{References}

1. Joint Committee on Vaccination and Immunisation. Meeting minutes.5 Oct 2011. London. Available from: http://webarchive. nationalarchives.gov.uk/20120907090205/http://www.dh.gov. uk/prod_consum_dh/groups/dh_digitalassets/@dh/@ab/ documents/digitalasset/dh_133598.pdf

2. Department of Health. Public Health England (PHE). The national flu immunisation programme 2015/16. London: PHE; 27 Mar 2015. Available from: https://www.gov.uk/government/ uploads/system/uploads/attachment_data/file/526144/ Annual flu letter 24 03 15superseded.pdf

3. Public Health England (PHE). Surveillance of influenza and other respiratory viruses in the United Kingdom: winter 2015 to 2016. London: PHE; May 2016. Available from: https://www. gov.uk/government/uploads/system/uploads/attachment_ data/file/526405/Flu_Annual_Report_2015_2016.pdf

4. Baguelin M, Flasche S, Camacho A, Demiris N, Miller E, Edmunds WJ. Assessing optimal target populations for influenza vaccination programmes: an evidence synthesis and modelling study. PLoS Med. 2013;10(10):e1001527. https://doi. org/10.1371/journal.pmed.1001527 PMID: 24115913

5. Pebody R, Warburton F, Ellis J, Andrews N, Potts A, Cottrell S, et al. Effectiveness of seasonal influenza vaccine for adults and children in preventing laboratory-confirmed influenza in primary care in the United Kingdom: 2015/16 end-of-season results. Euro Surveill. 2016;21(38):30348. https://doi. org/10.2807/1560-7917.ES.2016.21.38.30348 PMID: 27684603

6. Pebody RG, Green HK, Andrews N, Zhao H, Boddington N, Bawa $Z$, et al. Uptake and impact of a new live attenuated influenza vaccine programme in England: early results of a pilot in primary school-age children, $2013 / 14$ influenza season. Euro Surveill. 2014;19(22):20823. https://doi.org/10.2807/15607917.ES2014.19.22.20823 PMID: 24925457

7. Pebody RG, Green HK, Andrews N, Boddington NL, Zhao H, Yonova I, et al. Uptake and impact of vaccinating school age children against influenza during a season with circulation of drifted influenza A and B strains, England, 2014/15. Euro Surveill. 2015;20(39):30029. https://doi.org/10.2807/15607917.ES.2015.20.39.30029 PMID: 26537222

8. Grijalva CG, Zhu Y, Simonsen L, Mitchel E, Griffin MR. The population impact of a large school-based influenza vaccination campaign. PLoS One. 2010;5(11):e15097. https:// doi.org/10.1371/journal.pone.0015097 PMID: 21209872

9. King JC Jr, Cummings GE, Stoddard J, Readmond BX, Magder LS, Stong M, et al. SchoolMist Study Group. A pilot study of the effectiveness of a school-based influenza vaccination program. Pediatrics. 2005;116(6):e868-73. https://doi.org/10.1542/ peds.2005-1301 PMID: 16322144

10. King JC Jr, Lichenstein R, Cummings GE, Magder LS. Impact of influenza vaccination of schoolchildren on medical outcomes among all residents of Maryland. Vaccine. 2010;28(49):773742. https://doi.org/10.1016/j.vaccine.2010.09.064 PMID: 20933566

11. Centres for Disease Control and Prevention (CDC). ACIP votes down use of LAIV for 2016-2017 flu season. Atlanta: CDC; 2016. Available from: http://www.cdc.gov/media/releases/2016/ so622-laiv-flu.html

12. Gates P, Noakes K, Begum F, Pebody R, Salisbury D. Collection of routine national seasonal influenza vaccine coverage data from GP practices in England using a web-based collection system. Vaccine. 2009;27(48):6669-77. https://doi. org/10.1016/j.vaccine.2009.08.094 PMID: 19747574 
13. Bolotin S, Pebody R, White PJ, McMenamin J, Perera L, Nguyen-Van-Tam JS, et al. UK Severe Influenza Surveillance System (USISS) Steering Group. A new sentinel surveillance system for severe influenza in England shows a shift in age distribution of hospitalised cases in the post-pandemic period. PLoS One. 2012;7(1):e30279. https://doi.org/10.1371/journal. pone.0030279 PMID: 22291929

14. Public Health England (PHE). Eastern Region Public Health Observatory (Erpho). Acute hospital catchment populations 2009. London: PHE; Jun 2015. Available from: http://www. erpho.org.uk/viewResource.aspx?id=21919

15. Elliot AJ, Hughes HE, Hughes TC, Locker TE, Shannon T, Heyworth J, et al. Establishing an emergency department syndromic surveillance system to support the London 2012 Olympic and Paralympic Games. Emerg Med J. 2012;29(12):9546o. https://doi.org/10.1136/emermed-2011-200684 PMID: 22366039

16. Zhao H, Green H, Lackenby A, Donati M, Ellis J, Thompson C, et al. A new laboratory-based surveillance system (Respiratory DataMart System) for influenza and other respiratory viruses in England: results and experience from 2009 to 2012. Euro Surveill. 2014;19(3):20680. https://doi.org/10.2807/15607917.ES2014.19.3.20680 PMID: 24480060

17. Nielsen J, Mazick A, Andrews N, Detsis M, Fenech TM, Flores VM, et al. Pooling European all-cause mortality: methodology and findings for the seasons 2008/2009 to 2010/2011. Epidemiol Infect. 2013;141(9):1996-2010. https://doi. org/10.1017/S0950268812002580 PMID: 23182146

18. World Health Organization (WHO). International statistical classification of diseases and related health problems - 10th revision. Geneva: WHO; 2010. Available from: www.who.int/ classifications/icd/ICD10Volume2_en_2010.pdf

19. Ellis J, Iturriza M, Allen R, Bermingham A, Brown K, Gray J, et al. Evaluation of four real-time PCR assays for detection of influenza $A\left(\mathrm{H}_{1} \mathrm{~N}_{1}\right) v$ viruses. Euro Surveill. 2009;14(22):19230. https://doi.org/10.2807/ese.14.22.19230-en PMID: 19497254

20. Ellis JS, Curran MD. Simultaneous molecular detection and confirmation of influenza $\mathrm{AH}_{5}$, with internal control. Methods Mol Biol. 2011;665:161-81. https://doi.org/10.1007/978-160761-817-1_10 PMID: 21116801

21. Calder K, Bidwell S, Brunton C, Pink R. Evaluation of the Canterbury under-18 seasonal influenza vaccination programme. N Z Med J. 2014;127(1398):19-27. PMID: 25146858

22. Yin JK, Heywood AE, Georgousakis M, King C, Chiu C, Isaacs D, et al. Systematic Review and Meta-analysis of Indirect Protection Afforded by Vaccinating Children Against Seasonal Influenza: Implications for Policy. Clin Infect Dis. 2017;65(5):719-28. PMID: 28475770

23. Penttinen PM, Friede MH. Decreased effectiveness of the influenza $A\left(\mathrm{H}_{1} \mathrm{~N}_{1}\right)$ pdmog strain in live attenuated influenza vaccines: an observational bias or a technical challenge? Euro Surveill. 2016;21(38):30350. https://doi.org/10.2807/15607917.ES.2016.21.38.30350 PMID: 27684999

24. Caspard H, Mallory RM, Yu J, Ambrose CS. Live-Attenuated Influenza Vaccine Effectiveness in Children From 2009 to 20152016: A Systematic Review and Meta-Analysis. Open Forum Infect Dis. 2017;4(3): ofx111. https://doi.org/10.1093/ofid/ ofx111 PMID: 28852675

\section{License and copyright}

This is an open-access article distributed under the terms of the Creative Commons Attribution (CC BY 4.0) Licence. You may share and adapt the material, but must give appropriate credit to the source, provide a link to the licence, and indicate if changes were made.

This article is copyright of the authors, 2018. 